\title{
Do cálculo ao problema: um caminho a trilhar a partir de resultados científicos
}

\section{From calculus to the problem: a path to follow starting from scientific results}

Nara Vilma Lima Pinheiro

Universidade de São Paulo (USP), Faculdade de Educação, São Paulo, SP, Brasil.

E-mail: naravilmal@gmail.com

Resumo: Neste texto analisam-se como os resultados das investigações científicas do educador americano Carleton Washburne foram se transformando em orientações de práticas pedagógicas para o ensino de aritmética na escola primária. A análise toma por referência os experimentos desenvolvidos nas escolas de Winnetka, durante sua gestão como superintendente do ensino, no período de 1919 a 1943, a partir dos quais se estabeleceram novas bases epistemológicas sobre o ensino de aritmética. Os resultados evidenciam os primeiros passos na elaboração científica de saberes sobre o ensino de aritmética, fundamentados em novos objetivos e em uma nova organização curricular, que melhor delimitaram o campo do ensino de matemática na escola primária. O processo ocorreu em uma marcha de ensino que seguiu da compreensão do número, do domínio das combinações numéricas, à aplicação a situações da vida cotidiana, descritas em enunciados que estivessem ao alcance da linguagem infantil, tal como indicaram as investigações científicas.

Palavras-chave: Ensino de matemática; Escola primária; Resolução de problemas; História da educação matemática; Carleton Washburne.

Abstract: This paper analyzes how the results of scientific investigations by the American educator Carleton Washburne have become guidelines for pedagogical practices for the teaching of Arithmetic in elementary school. The analysis takes as reference the experiments developed in the schools of Winnetka during Washburne's management as superintendent of teaching in the period from 1919 to 1943, from which new epistemological bases were established for the teaching of Arithmetic. The results show the first steps in the scientific elaboration of knowledge about the teaching of Arithmetic, based on new objectives and a new curricular organization, which best delimited the field of mathematics teaching in elementary school. The process took place in a teaching journey that followed the understanding of the number, the mastery of numerical combinations, and the application to everyday situations life, described in statements that were available in?/to children's language, as indicated by scientific investigations.

Keywords: Mathematics teaching; Elementary school; Problem solving; History of mathematical education; Carleton Washburne.

Recebido em: 09/09/2020

Aprovado em: 15/05/2021 


\section{Considerações iniciais}

Que dificuldades as crianças apresentam na resolução de problemas aritméticos? Qual método se mostra mais adequado ao ensino da resolução de problemas? As crianças resolvem mais facilmente problemas aritméticos que estão dentro de sua própria experiência, ou quando eles envolvem situações cotidianas do mundo adulto? As operações devem ser ensinadas antes dos problemas ou o contrário? Questões como essas, embora pareçam atuais, na realidade, já vinham sendo discutidas desde o início do século 20, tempo em que a pedagogia científica buscava na psicologia experimental meios de legitimar suas práticas. Para uma exposição aprofundada sobre a pedagogia científica e o ensino de matemática, consultar Pinheiro (2017).

Em perspectiva histórica, nota-se que não se tratava de investigações para saber se a resolução de problemas deveria ou não ser ensinada na escola, tampouco se seria importante no currículo de matemática. Ao que parece, ao lado das quatro operações fundamentais, a resolução de problemas se apresentava como um dos conhecimentos técnicos úteis que as crianças necessitariam na vida adulta. No entanto, as crianças apresentavam muitas dificuldades em sua aprendizagem, levando psicólogos, professores, diretores, dentre outros, a investirem em estudos científicos que viabilizassem a eficácia do sistema escolar, de modo a garantir que cada um tivesse acesso aos saberes úteis à vida em sociedade. Investigações como essas levaram as portas das escolas a se abrirem aos experts, sujeitos que se destacaram no ofício docente por seus conhecimentos teóricos e práticos, que, em nome da ciência, fizeram chegar ao campo social uma maneira inédita de examinar e avaliar os fenômenos escolares (HOFSTETTER; SCHNEWUWLY; FREYMOND, 2017). A esses experts foi dada a tarefa de produzirem saberes sobre o sistema escolar, segundo uma lógica organizada por regras específicas do mundo científico, de modo a fornecerem respostas práticas ao problema do rendimento e da eficiência do ensino primário. Por essa tarefa, compreende-se uma ação que envolve "[...] a modificação pelo indivíduo de seu ambiente (no sentido de ambiente material ou conceitual)" e implica uma finalidade (REY, 2006 apud MORAIS; VALENTE, 2020, p. 7-8). Nos Estados Unidos, tratava-se de fornecer aos reformadores educacionais ferramentas de decisão que justificariam uma reorganização do aparelho escolar (PINHEIRO, 2017).

Carleton Washburne foi um dos sujeitos que se destacou por suas experiências educacionais com o ensino individualizado, razão pela qual the foi solicitado por autoridades educacionais locais a organizar, em 1919, o sistema escolar público de Winnetka, uma pequena vila nos subúrbios de Chicago. Como expert, Washburne teve liberdade para pôr em prática um plano mais ambicioso do que vinha desenvolvendo desde 1914 na escola anexa à Escola Normal de São Francisco, resultando no desenvolvimento e na implementação de materiais curriculares de ciências, e na publicação de sua tese de doutorado intitulada $A$ science curriculum based on reseach (MEUER, 1988).

O trabalho desenvolvido na Escola Normal de São Francisco gerou muitas críticas por se tratar de experiência realizada em um ambiente privilegiado, haja vista as classes serem de poucos alunos, sob a regência de um professor e de seu assistente. Do ponto de vista de seus críticos, isso dificultava que os resultados obtidos fossem passíveis de serem generalizáveis à prática educativa (WASHBURNE; MARLAND, 1963). 
No tempo em que esteve à frente das investigações desenvolvidas em escolas de Winnetka, no período de 1919 a 1943, Washburne publicou resultados que contribuíram para o rendimento e a eficiência do ensino, com efeito direto na prática pedagógica dos professores, e serviram como justificativa para a reformulação do sistema escolar sob sua direção. Os estudos desenvolvidos recentemente por Pinheiro (2021a, 2021b) sobre a trajetória profissional de Washburne e a circulação de suas ideias, evidenciaram que os resultados das investigações realizadas por este pedagogo ultrapassaram as fronteiras estadunidenses e se tornaram referência internacional e intercontinental como modelo de práticas inovadoras no contexto das ideias escolanovistas, sobretudo quando passou a fazer parte da New Education Fellowship (NEF), importante organização internacional criada com o objetivo de promover a educação nova e desenvolver uma expansiva rede internacional de colaboradores para a difusão de seus ideais (RABELO, 2016).

Ao se tornar referência, é de se conjecturar que a expertise pedagógica de Washburne produziu saberes sobre o ensino na escola primária passíveis de sistematização em diversos contextos, sobretudo no ensino de matemática. Assim, interessa saber:

- Como suas investigações experimentais foram se transformando em orientações para práticas pedagógicas?

- Quais resultados foram passíveis de sistematização para o ensino de aritmética na escola primária?

$\mathrm{Na}$ tentativa de responder a essas questões, recorreu-se à análise dos resultados de suas investigações, publicados em periódicos educacionais estadunidenses, e sua sistematização na coleção de aritméticas, publicada em 1927.

\section{Entre práticas pedagógicas e experimentos científicos: os problemas aritméticos}

A expertise pedagógica de Washburne teve origem na própria docência, atuando inicialmente como professor em escolas rurais e, na sequência, como pesquisador em escolas anexas à Escola Normal de São Francisco. É nesta última função que, ao assumir o cargo de superintendente do ensino das escolas de Winnetka, seu trabalho passou a se destacar. Em específico, ao organizar um corpo de experts que ficou conhecido como Committe of Seven (Comissão dos Sete), criada com a finalidade de discutir estudos sobre os currículos escolares e divulgar os resultados em conferência anual. Fizeram parte dessa comissão Harry N. Gillet, diretor da escola primária da Universidade de Chicago, Raymond Osborne, diretor associado e posteriormente diretor da Francis W. Parker School de Chicago, J. R. Harper, Orville T. Bright, Howard Storm e William Hamilton, todos superintendentes de escolas no norte de Illinois, e o próprio Carleton Washburne (WASHBURNE; MARLAND, 1963).

Ao assumir a presidência dessa organização, em meados de 1921, Washburne incluiu, como meta principal, as investigações científicas nos currículos escolares, haja vista que os estudos desenvolvidos por comissões anteriores se fundamentavam em discussões empíricas, nas experiências de vida, em leituras de seus membros, e não em pesquisa experimental. As investigações científicas desenvolvidas pela comissão gerenciada por Washburne baseavam-se nos estudos psicológicos sobre o desenvolvimento infantil, em particular sobre as diferenças individuais, e tinham por objetivo investigar hipóteses sobre as dificuldades de aprendizagem das crianças, a fim 
de torná-las orientações pedagógicas sobre o que, quando e como ensinar na escola primária.

O trato de problemas pedagógicos via métodos científicos não foi uma criação de Washburne. Ele remonta pelo menos ao início do século 20, quando a psicologia experimental adentra o espaço escolar estadunidense, visando substituir a maneira empírica de se tratar a educação, por um modo científico de examinar, avaliar e lidar com os problemas pedagógicos. Tratava-se de buscar, em análises estatísticas, os dados coletados e relatados, com detalhes de precisão, por meio de testes psicológicos e pedagógicos, respostas para o pouco rendimento e a ineficiência do ensino. Antes de Washburne, psicólogos estadunidenses já vinham realizando algumas tentativas, como, por exemplo, Thorndike e Ballard. Mas, diferentemente dos psicólogos, que faziam suas observações em laboratórios, e testavam em escolas, as investigações científicas de Washburne foram desenvolvidas dentro da própria escola. (PINHEIRO, 2017).

No período de 1919 a 1943, os resultados dessas investigações foram divulgados em importantes periódicos da época, tais como Education Research Bulletin, Elementary School Journal, Journal of Education Research e Progressive Education, permitindo a validação e o reconhecimento científico desejado. Para o que interessa discutir neste texto, as publicações nesses periódicos evidenciam os principais assuntos aritméticos pesquisados, desenvolvidos e aprofundados ao longo do trabalho da Comissão dos Sete.

Uma das primeiras ações da Comissão foi investigar se as operações fundamentais da aritmética ensinadas nas escolas estavam em conformidade com as necessidades e práticas sociais. A amostragem se constituiu de membros de organizações como Rotary Club, clubes comerciais e associações de pais, cujos membros foram considerados "[...] um estrato superior, inteligente e bem-sucedido da sociedade" (WASHBURNE, 1926, p. 60, tradução nossa). Todos os participantes da investigação foram submetidos aos testes aritméticos de Cleveland Survey, envolvendo operações com inteiros e frações. Os resultados evidenciaram que os adultos superavam as crianças em processos mais fáceis e elementares (adição e subtração) do que em processos mais difíceis e avançados (multiplicação, divisão e frações), nos quais as crianças se mostraram superiores. A justificativa para esses resultados advinha do fato de as operações fundamentais com inteiros, em especial adição e subtração, serem usadas constantemente na vida, enquanto as frações pouco apareciam em situações fora da sala de aula (WASHBURNE, 1926). Essa investigação corroborava resultados já obtidos em testagens desenvolvidas, em 1917, por Paul H. Hanus e Harry G. Gaylord, sobre a capacidade aritmética de funcionários de uma empresa e de uma loja de departamentos, exceto pelo fato de que a investigação da Comissão indicaxva que a adição era mais utilizada na vida, do que a multiplicação. (WASHBURNE, 1926).

Os resultados da investigação foram levados para discussão na reunião anual da associação de superintendentes de 1925. Nessa reunião, a discussão girou em torno da redução dos conteúdos aritméticos de modo que se adequassem às demandas da sociedade, em vez de exigirem dos alunos da escola primária um nível elevado de habilidades gerais que não seriam utilizadas, tais como o ensino de multiplicação, de divisão de inteiros e das frações, em suas formas mais complexas. No caso do ensino de frações, este não deveria ultrapassar os princípios básicos, suficientes à 
maioria das pessoas. Quanto à multiplicação e divisão envolvendo números inteiros, a recomendação seria reduzir os padrões de graduação para o nível dos requisitos exigidos para os alunos da sétima série. O contrário ocorria com a adição e a subtração de inteiros, ambas consideradas essenciais à demanda constante da vida. Neste caso, a recomendação era elevar consideravelmente o ensino de ambas as operações (WASHBURNE, 1926). A análise desses resultados indica que a função social da escola precisava ser repensada, pois transmitia conhecimentos pouco úteis à vida. Justificase, assim, a base sobre a qual deveria ser estruturado o ensino de aritmética, isto é, conectado às necessidades sociais, às demandas da vida cotidiana.

Na sequência, foi publicado um extenso estudo conduzido por Washburne e Osborne (1926a) sobre as dificuldades das crianças em solucionar problemas aritméticos. A ideia principal foi verificar se essas dificuldades eram decorrentes dos problemas, ou dos métodos de ensino. Em um primeiro momento, eles decidiram investigar se os enunciados dos problemas estavam adequados ao ensino na escola primária. Em meio a várias hipóteses, os autores se propuseram a investigar, por meio de testes, cinco questões. A primeira se referia à incapacidade da criança visualizar uma dada situação tratada em um problema. A investigação considerou uma série de testes com questões simples e ilustrações que representavam a situação tratada no problema, para que a criança buscasse aquela que melhor se adequasse ao proposto. Os resultados indicaram que não havia dificuldade na leitura de problemas simples que impedissem as crianças de visualizarem a situação envolvida.

O passo seguinte foi entender se existia alguma relação entre a capacidade de resolver problemas e a capacidade de fazer uma análise formal. Em busca de respostas, foi elaborada uma bateria de testes com problemas cuja solução requeria uma ou duas operações, com enunciados típicos da vida infantil. Ao final da investigação, os resultados evidenciaram pouca relação entre a capacidade de resolver problemas e a capacidade de fazer análise formal, contrariando ideias preconcebidas pela Comissão, de que haveria uma forte relação. Isso levou os pesquisadores a repetirem a investigação, para que se pudesse melhor determinar se o treinamento na análise formal era definitivamente útil na resolução de problemas pelas crianças. No entanto, o mesmo resultado se manteve. Quanto à terceira questão, a comissão decidiu investigar até que ponto a falta de familiaridade com a situação envolvida no problema, ou com materiais com os quais lidava o problema, causaria a falha na resolução correta. Desta vez, foram utilizados pares de problemas que envolviam uma situação familiar, e outra, não. Nesse caso, os resultados indicaram que a falta de familiaridade com as situações envolvidas nos problemas era fator significativo da causa das dificuldades das crianças na resolução destes.

A penúltima questão da pesquisa levou a Comissão a investigar se os alunos que resolviam problemas mentalmente conseguiam aplicar suas habilidades na resolução de problemas escritos. As pesquisas evidenciaram que a capacidade de resolver um problema mentalmente não era, em muitos casos, acompanhada pela capacidade de resolver um tipo de problema envolvendo números tão grandes que necessitassem figurar no papel, mesmo que a criança conseguisse fazê-lo corretamente. Essa discrepância desaparecia, consideravelmente, nos graus de escolaridade mais altos, nos quais os processos mecânicos eram mais automáticos. A quinta e última questão de pesquisa envolveu a investigação da dificuldade em usar 
a mecânica da aritmética, resultando na constatação de que esta era uma fonte muito comum de erro.

Na continuidade da pesquisa, Washburne e Osborne (1926b) fizeram um estudo mais intensivo e extensivo relativo a três métodos de treinamento das crianças para resolver problemas. Inicialmente, cada professor responsável por uma classe em experimento deveria estudar minuciosamente cada método que usaria com a turma. Caso houvesse dúvidas quanto aos métodos, elas deveriam ser enviadas a Washburne. Em reunião especial com todos os professores, diretores e superintendentes participantes da investigação, Washburne demonstrou como resolver problemas de acordo com três métodos, de modo a assegurar que todos os envolvidos compreendessem plenamente a diferença entre cada um deles (WASHBURNE; OSBORNE, 1926b).

Nenhuma técnica especial seria desenvolvida pelo Método Um. A ideia principal era fornecer às crianças um grande número de problemas para resolver. Inicialmente, o professor deveria trabalhar vários problemas no quadro com ajuda dos alunos e, na sequência, eles trabalhariam sozinhos. Caso houvesse dificuldade em resolver algum problema, a criança seria orientada a deixá-lo de lado e passar para o próximo. 0 professor poderia oferecer alguma ajuda, mas nunca ensinar um método para que o aluno pudesse resolvê-lo. A ajuda deveria limitar-se à leitura do problema, ou à elaboração de uma ou duas questões para descobrir qual era a dificuldade. A essência do Método Um era levar a criança a resolver a maior quantidade possível de problemas a ponto de serem capazes de fazer generalizações, por si mesmas, como resultado da resolução de muitos problemas.

Com relação ao Método Dois, diferentemente do que ocorre no anterior, os professores treinariam as crianças para a resolução de problemas, de acordo com a técnica de análise, em seis etapas:

1. Ler o problema com cuidado.

2. Determinar o que deve ser encontrado.

3. Determinar quais elementos no problema ajudam a encontrar a resposta.

4. Decidir qual processo usar.

5. Estimar, aproximadamente, a magnitude do resultado.

6. Resolver o problema (WASHBURNE; OSBORNE, 1926b, p. 297, tradução nossa).

Por meio do Método Dois, o professor deveria treinar a classe até ter certeza de que a maioria dos alunos conhecia e sabia usar bem cada uma das seis etapas. Cada um, antes de prosseguir na operação mecânica, deveria indicar para cada problema o que deveria ser encontrado, e o que lhe era dado. Após o tempo de treinamento, as crianças passariam a trabalhar individualmente na resolução. Neste caso, o professor poderia orientar individualmente cada aluno, desde que sua ajuda incluísse apenas as seis etapas de resolução de problemas. O objetivo principal do Método Dois não era a resolução da maior quantidade possível de problemas, mas o treinamento completo na técnica de analisar cada um antes de resolvê-lo.

Já o Método Três consistia em treinar a criança para a observação de analogias entre os problemas escritos mais difíceis, e os orais simples do mesmo tipo. Tratava-se de trabalhar vários deles e fazer com que os alunos criassem problemas orais simples e semelhantes aos escritos em discussão, resolvessem os problemas orais, descobrissem o processo utilizado, e o aplicasse na resolução do problema escrito. Quando o professor estivesse convencido de que os alunos sabiam construir problemas orais 
simples, e aplicar o processo de resolução aos problemas escritos, o aluno estaria apto a trabalhar individualmente. A recomendação, ao professor, era de que ele auxiliasse as crianças individualmente, fazendo a analogia entre um problema escrito e um problema oral simples e similar, tomando o cuidado para não trabalhar com o método de análise. A essência do Método Três não era a resolução de muitos problemas, como no Método Um, tampouco o treinamento na técnica de analisar problemas, como no Método Dois, mas o treinamento de cada criança para o hábito de ver a relação entre os problemas escritos mais difíceis, e os problemas orais simples, similares aos que ele sabia resolver.

Quanto à correção dos problemas, procedimento comum aos três métodos, caberia ao professor corrigir, e, no caso de haver algum erro, a criança retornaria a trabalhar com os problemas considerados incorretos. Também era comum que, ao menos duas vezes por semana, ou com a frequência que os alunos precisassem, os primeiros 15 minutos de aula fossem dedicados à resolução de problemas com o método trabalhado pela turma.

Ao final da investigação, a Comissão concluiu que as crianças que não aprenderam nenhuma técnica especial de resolução de problemas (Método Um), mas simplesmente resolveram muitos problemas, superaram aquelas que passaram tempo aprendendo pelo método de análise (Método Dois), ou de analogia (Método Três). Dito de outro modo, treinar as crianças por meio de um método formal se apresentou menos eficaz do que, simplesmente, dar-Ihes muitos problemas e ajudar cada aluno com qualquer dificuldade especial que pudesse encontrar. Os investigadores não deixaram de observar que, nos três casos investigados, os alunos obtiveram ganhos notáveis, indicando claramente que a atenção concentrada, mesmo por algumas semanas, na prática de resolução de problemas por qualquer que fosse o método, gerava benefícios.

Para além de indicar que não havia um método mais adequado, mas um treinamento para a resolução de problemas, surgiram recomendações pedagógicas referentes à elaboração dos problemas, as quais deveriam ser construídas de modo a apresentar situações reais e familiares às crianças. Na análise dos procedimentos dos três métodos, percebeu-se que eles tinham em comum a revisão, tomada como repetição da resolução incorreta de um problema. Assim, a repetição foi tomada como expediente pedagógico destinado a fazer o aluno fixar a matéria aprendida e se preparar para o passo seguinte.

Notou-se, ainda, pelas orientações dadas aos professores participantes do experimento, que, no uso de qualquer um dos três métodos, seriam necessários saberes específicos, saberes advindos da expertise pedagógica de Washburne. Ao que parece, no caso do Método Um, os problemas foram utilizados como recurso didático, aplicações práticas para o ensino das operações. Nesse caso, os saberes exigidos dos professores se referiam a conhecer os problemas ensinados e os saberes aritméticos neles solicitados. Já no caso dos métodos de análise e analogia, os saberes solicitados aos professores seriam de outra natureza, diziam respeito a ensinar as crianças a resolverem problemas por meio de um passo a passo, de regras específicas. Não bastaria apenas conhecer os problemas e a aritmética neles solicitada, o próprio problema se tornava um saber aritmético, com orientações e sugestões próprias de como explicálos às crianças, tornando-os ensináveis. Esse modo de pensar a resolução de problema, 
como saber aritmético, já vem sendo apontado nas pesquisas historiográficas de Bertini, Morais e Valente (2017).

Inconformados com esses resultados, Washburne e seus colaboradores decidiram continuar com as investigações. O foco da lupa se ajustou para a ordem de ensino dos processos mecânicos da aritmética e dos problemas. Tratava-se de saber se as crianças adquiriam maior habilidade se os processos mecânicos fossem aprendidos por meio de situações dentro de suas experiências, e aplicados durante o período de prática diretamente à resolução de problemas; ou se os processos fossem aprendidos e praticados sem referências concretas e, posteriormente, aplicados à resolução de problemas (WASHBURNE, 1927a). Dito de outro modo, se o ensino deveria partir das operações fundamentais, sem considerar os problemas ou situações concretas até que a mecânica da aritmética estivesse, razoavelmente, bem dominada; ou se o ensino das operações deveria se dar a partir de problemas verbais, com aplicação constante. Neste experimento, foram utilizados o Método de Problema e o Método da Mecânica, por um período de seis semanas.

O Método de Problema se baseava na ideia de que os alunos aprenderiam efetivamente um processo matemático se confrontados com um problema que demandasse o uso de tal processo. Para que isso viesse a ocorrer, o problema deveria ser real, envolver uma situação familiar e despertar o interesse em resolvê-lo. Por este método, o professor ensinaria a resolver problemas a partir da leitura conjunta, chamando atenção para as situações envolvidas, questionando-os sobre problemas semelhantes, mostrando a resolução, trabalhando em conjunto em busca da solução até os alunos estarem aptos a resolver. Já pelo Método da Mecânica, os professores ensinariam os processos matemáticos, as operações, de forma independente, sem uso de problemas; esses só seriam empregados quando os alunos tivessem certo domínio das operações. Em ambos os métodos foram utilizados os mesmos tipos de problema.

Segundo Washburne (1927a), a principal dificuldade dessa investigação foi encontrar problemas que atendessem a essas orientações. Isso motivou a equipe de investigadores a trabalhar na elaboração de problemas aritméticos a ser utilizados, os quais foram submetidos à análise crítica dos professores participantes do experimento. A elaboração e a seleção desse conjunto de problemas foram consideradas por Washburne como um dos resultados mais valiosos da investigação.

Em se tratando do experimento em si, os dados não evidenciaram distinção significativa que causasse dificuldades se a aprendizagem se iniciasse pela resolução de problemas práticos, ou pela mecânica da aritmética, até que ela tivesse sido dominada. Em contrapartida, o treinamento minucioso e completo de quaisquer das duas técnicas produziu bons resultados, independentemente de a mecânica da aritmética ser ou não introduzida por meio de problemas, ou constantemente usada em problemas práticos enquanto estavam sendo aprendidas.

Quanto à dificuldade que as crianças tinham com a resolução de problemas aritméticos, ela era decorrente da linguagem ou da redação dos próprios problemas, e não dos alunos. Além disso, os problemas não despertavam o interesse infantil, pois eram problemas que interessavam aos adultos, e a criança não compreendia a razão de resolvê-los (WASHBURNE; MORPHETT, 1928). No exemplo I, a seguir, tem-se um problema que interessaria aos adultos, o qual envolvia uma situação irreal no universo 
infantil, e, no exemplo II, um problema que interessaria às crianças, pois envolvia situações familiares:

I) Uma companhia telefônica tinha 62 carretéis de arame. Ontem, recebeu 11 de uma fábrica próxima. Hoje, recebeu mais 39. Então, 15 deles foram usados. Quantos carretéis de arame a empresa deve ter agora?

II) Eu tinha 55 bolinhas de gude. Ontem, meu pai me deu 23 bolinhas novas. Hoje, meu irmão me deu 35 bolinhas das que ele tinha. Então, eu dei ao meu amigo 15 delas. Eu me pergunto se perdi alguma. Quantas bolinhas devo ter agora? (WASHBURNE; MORPHETT, 1928, p. 221, tradução nossa).

A partir da constatação de que o enunciado do problema era o vilão do ensino, o mais importante a fazer era elaborar problemas familiares e infantis, isto é, problemas que as crianças pudessem realmente imaginar a situação; enunciados nos quais o personagem principal de cada problema deveria ter uma razão para resolvê-lo. Ou seja, se a criança estivesse na situação descrita no problema, ela sentiria necessidade de encontrar a solução; os enunciados, com o vocabulário e a estrutura da sentença, deveriam estar dentro da capacidade de leitura da criança que deveria resolvê-lo. (WASHBURNE; MORPHETT, 1928).

Como é possível notar, a partir dos resultados das investigações desenvolvidas pela Comissão dos Sete, as orientações pedagógicas de Washburne se voltaram à elaboração e/ou à escolha dos problemas aritméticos, e não ao como ensinar a resolver problemas. O que estava em jogo era a superação de enunciados que remetessem às situações da vida adulta, e tratassem os problemas como aplicação direta de conteúdos aprendidos anteriormente. Não se tratava de abolir do ensino os problemas de aplicação, mas matematizar situações reais e familiares às crianças. Suas orientações evidenciam que a estrutura semântica dos problemas seria muito mais importante do que a estrutura sintática, sendo determinante na resolução de problemas. As diferenças semânticas nos diversos problemas se refletiam na capacidade das crianças em representá-los matematicamente.

Como vimos até aqui, as primeiras experiências desenvolvidas por Washburne estavam focadas no que e como ensinar aritmética para as crianças da escola primária. No entanto, ele também se preocupou com o quando ensinar, em que graus do ensino e em que ordem colocar os vários tópicos aritméticos. Até então, os estudos científicos tinham se dedicado ao como ensinar, deixando de lado a idade mais adequada para tal. E, sob a ótica de Washburne (1928), talvez este fosse um dos motivos da dificuldade da aprendizagem de algumas crianças, isto é, conteúdos ensinados antes da maturidade infantil. Afinal, a ordem lógica da própria aritmética estaria adequada à ordem psicológica do desenvolvimento infantil?

A hipótese de Washburne (1934, p. 3, tradução nossa) era de que os matemáticos e autores de livros de aritmética organizavam os conteúdos a ensinar na escola primária sem ter "[...] uma base clara, concisa e lógica para discriminar o que deve ser incluído do que deve ser excluído". A ideia principal foi submeter ao crivo da ciência todos os tópicos aritméticos ensinados nas escolas estadunidenses a fim de descobrir a idade mais adequada para ensiná-los na escola primária.

A tabulação dos tópicos aritméticos com relação ao momento em que eram ensinados evidenciou uma diversidade de práticas, sendo a mais marcante o grau em que se ensina pela primeira vez a operação de adição, que ora aparecia na primeira 
série, ora na segunda e, por vezes, na terceira série da escola primária. Esse dado foi considerado relevante e mereceu ser investigado para melhor definir se haveria algum benefício importante ao ensinar a adição na primeira série ou na segunda série, ou se o ensino poderia ser adiado até a terceira série. Nesse sentido, os resultados da investigação mostraram que os alunos que iniciaram a aprendizagem da aritmética formal na primeira série tiveram uma vantagem distinta, em termos de capacidade aritmética, sobre os alunos que iniciaram na segunda série, e estes últimos tiveram a mesma vantagem sobre os que iniciaram na terceira série.

Retomando a investigação sobre a graduação psicológica dos conteúdos, em 1930, Washburne apresentou o primeiro relatório com resultados mais significativos sobre o nível de classificação dos tópicos aritméticos (KILPATRICK, 1992). Nesse relatório, ele alegou ter descoberto a idade mental mínima em que cada um dos tópicos aritméticos deveria ser ensinado (PINHEIRO; VALENTE, 2016).

As investigações continuaram por toda a década de 1930 e, segundo Kilpatrick (1992, p. 19, tradução nossa), tiveram "[...] uma influência inquestionável na organização do currículo aritmético" induzindo os reformadores do currículo a mudar tópicos considerados elevados em algumas séries e a separar outros que se relacionam matematicamente.

Mas isso não ocorreu sem críticas, sem aquilo que Chartier (1990, p. 17) denominou por lutas de representações, advindas dos campos de concorrências e competições "[...] cujos desafios se enunciam em termos de poder e de dominação", estratégias e táticas "[...] que tendem a impor uma autoridade à custa de outros, por elas menosprezados, a legitimar um projeto reformador ou a justificar, para os próprios indivíduos, as suas escolhas e condutas".

Vista desse modo, a produção de novos saberes sobre o ensino de aritmética na escola primária evidencia a tensão entre campos distintos da profissão. É o que se pode notar nas críticas publicadas por Louis E. Raths (RATHS, 1932a, 1932b), assistente de pesquisa no Bureau of Educational Research, orgão de profissionalização da pesquisa em educação, no período de 1931 a 1933. É importante observar que, antes de assumir esse posto no Bureau, Raths foi colaborador de Washburne nos projetos relacionados à graduação dos tópicos aritméticos. Quando participou das investigações dirigidas por Washburne, Raths foi assistente de pesquisa de Harry O. Gillet, diretor da escola primária da Universidade de Chicago e membro da Comissão dos Sete, contribuindo, no campo acadêmico, para o avanço teórico da produção de novos saberes científicos.

Em relação ao lugar ocupado por Washburne, o campo educativo, os saberes por ele produzidos foram de ordem prática, elaborados com a finalidade de dar melhor rendimento e eficiência ao ensino público. No entanto, não se tratam de saberes empíricos, oriundos da observação sem comprovação científica. Os saberes produzidos por Washburne se fundamentavam nos instrumentos psicológicos e estatísticos que ele mobilizou em suas investigações. Embora não fosse um pesquisador da Academia, a mobilização de instrumentos científicos, a submissão de procedimentos por meio de revistas especializadas, a avaliação por pares, e a gestão de relatórios a diferentes públicos endossaram sua credibilidade, seu prestígio internacional, reforçando seu papel de expert em educação.

Em seus textos, Raths tecia críticas quanto às técnicas e instrumentalização utilizadas pela Comissão. Suas críticas principais se referiam à inadequação de alguns 
dos testes utilizados no experimento, sobretudo o teste de subtração, considerado muito difícil. Também criticou a validade e confiabilidade dos testes e os critérios de prontidão, considerando exagerada a inter-relação entre idade mental e a prontidão para determinado tópico aritmético (KILPATRICK, 1992).

Em 1938, as críticas de Raths ganharam um novo aliado: o psicólogo educacional William Brownell, da Universidade de Duke (EUA), que, além de criticar a concepção de maturação, a instrução e os instrumentos usados nas investigações, acusava a Comissão dos Sete de desviar a pesquisa de questões sociais fundamentais (BROWNELL, 1938).

Ao que parece, as críticas ao trabalho da Comissão dos Sete publicadas nesses artigos e as respostas de Washburne $(1932,1939)$ são de duas naturezas: a primeira é referente à utilização de instrumentos psicológicos pelo professor, visto como pessoa não autorizada a utilizá-los, haja vista não ter os saberes necessários para tal; a segunda revela diferentes posicionamentos psicológicos quanto à teoria da aprendizagem. Nesse sentido, de um lado, tem-se Brownell, defensor da teoria da aprendizagem significativa, e Raths, adepto da teoria da experiência ${ }^{1}$, de Dewey, na qual a aprendizagem ocorre por meio da atividade pessoal e experimental do aluno. De outro, Washburne, adepto, em certa medida, do conexionismo de Thorndike, sobretudo da teoria do Drill, do treino visando a eficiência (rapidez e precisão) na aprendizagem dos commons essentials, e da teoria de Dewey, com atividades grupais e criativas, fundamentadas nos princípios progressistas de considerar os interesses infantis. (ZILVERSMIT, 1993).

Segundo Bertini, Morais e Valente (2017, p. 29), o embate entre diferentes posicionamentos psicológicos envolvendo a aritmética já vinha ocorrendo nessa época, sobretudo entre as ideias de Thorndike e Brownell, dois psicólogos que "[...] viam nos problemas matemáticos um meio de legitimar as teorias de aprendizagem por eles defendidas". Apesar de inseridos em um campo de concorrências e competições, os saberes produzidos pela Comissão dos Sete foram chancelados como um critério importante a se considerar na reformulação do currículo em todos os Estados Unidos da América. (MILLER, 1958).

\section{Sistematização de saberes aritméticos produzidos por Washburne}

Aos poucos, os resultados obtidos nas investigações realizadas por Washburne se tornaram orientações pedagógicas, e foram sistematizados em um processo que envolveu observação, investigação e classificação das experiências vividas, passando a ser aceitos de modo mais genérico, tornando-se consensos pedagógicos, passíveis de generalização e de objetivação. A sistematização desses saberes pode ser lida no manual para professores da coleção intitulada Washburne individual arithmetic, de autoria de Washburne (1927b, 1927c) em colaboração com professores e pesquisadores do Departamento de Educação Pública de Winnetka.

Essa coleção foi elaborada a partir de investigações científicas desenvolvidas em sala de aula, algo em voga à época, tendo em vista a preocupação com melhor rendimento e eficiência do ensino, e que envolveram 60 professores, que em oito anos observaram, analisaram, submeteram a testes seus alunos e avaliaram os resultados

'Ao tempo que escrevia suas críticas, Raths estava trabalhando nas investigações realizadas pela Progressive Education Association, que ficaram conhecidas como Eight-Year Study. 
obtidos. Esses resultados deram origem, em 1925, à primeira versão experimental da coleção de aritméticas, que inicialmente eram mimeografadas. Utilizada sob a supervisão de professores, a coleção era de tempos em tempos reeditada e ampliada, com o objetivo de suprir os pontos que se apresentaram deficientes. Para tanto, criouse um comitê, especialmente para tratar da elaboração, do aperfeiçoamento e da possível publicação dos livros produzidos. Essa ação resultou na versão final da coleção de aritméticas de Washburne (1927b, 1927c) para uso em outras escolas, publicada em 1927 pela World Book Company. Tratava-se de uma coleção sob medida, ajustada à maturidade infantil, de modo a servir ao ensino individualizado, no qual cada criança progrediria em seu ritmo, autocorrigindo-se por meio de respostas dadas e testes apropriados a cada novo tópico. Com esses materiais, os professores não precisariam de exemplos adicionais.

Segundo Washburne (1927b), sua coleção seria de grande valia, independentemente do método adotado, para a prática sistemática da aritmética, pois ela forneceria aos professores a maior parte do trabalho prático. Do seu ponto de vista, o trabalho prático sobrecarregava os professores, que deveriam lançar mão de suas horas de folga para preparar exercícios para seus alunos, e isso não seria eficaz, pois não teriam sido cuidadosamente preparados, com resultados de intenso trabalho de testagem ao longo de anos. Quando bem preparados, os materiais para ensino de aritmética resultariam em maior eficiência e rendimento do ensino.

A coleção tinha 12 livros destinados aos alunos, abrangendo todo o curso primário. Em se tratando dos professores, havia dois livros a eles destinados: um contendo as respostas do Test book e outro intitulado Teacher's manual, com detalhamento de como proceder em cada uma das etapas tratadas nos exemplares dos alunos. Segundo as orientações do manual, a ajuda do professor ao aluno não se daria por meio de explicações, mas por meio de indicações, em exemplo particular, de como a dificuldade deveria ser superada. Nesse sentido, as instruções deveriam ser sempre concretas, em vez de abstratas e analíticas.

A marcha do ensino deveria seguir, da compreensão do número por meio de muitos jogos e exercícios motivadores, e testes de velocidade. Depois, o domínio das combinações de cada operação, no desenvolvimento passo a passo, sem definições, regras ou fórmulas, com testes de diagnósticos, de modo a evidenciarem os pontos fracos da aprendizagem. E, finalmente, pela aplicação das combinações dos processos mecânicos às situações da vida, discutidos em enunciados ao alcance da linguagem infantil, tal como indicaram as investigações do Comitê. A dinâmica de aprendizagem compreendia o domínio dos fatos e processos envolvidos e uma intensa prática na resolução de problemas que estivessem dentro da experiência infantil. Inicialmente, a criança treinaria apenas a operação aprendida para, na sequência, treiná-la em conjunto com outra operação. Assim, por exemplo, se a criança tivesse aprendido a adição, na ordem das unidades, treinado suas várias combinações e a resolução de problemas, a próxima etapa seria o treinamento da subtração, também na ordem das unidades e nos mesmos moldes de trabalho. No entanto, no momento de automatizar, de reter na memória o aprendido, ela treinaria as duas operações em conjunto até o momento de aprender outra operação. Sempre em um processo de retomada do conhecimento anterior acrescido ao novo. A multiplicação só viria a aparecer após a aprendizagem das operações de adição e subtração na ordem dos milhares. 
$\mathrm{Na}$ análise dos enunciados dos problemas, percebe-se que as sentenças eram curtas, buscando reduzir a complexidade da linguagem, ao escolher palavras e situações de uso mais frequentes no cotidiano infantil. Seguem os exemplos I e II dos enunciados dos problemas sobre adição e subtração presentes no livro do aluno:

I. Tom precisa de um lápis de 8 centavos e uma caneta de 8 centavos. Quanto dinheiro ele precisa pagar por eles? (WASHBURNE, 1927c, p. 9, tradução nossa).

II. Eu ganho um centavo por dia. Eu quero um avião de brinquedo que custa 15 centavos. Eu tenho 7 centavos agora. Quantos dias mais devo esperar? (WASHBURNE, 1927c, p. 15, tradução nossa).

A cada novo passo aprendido em uma operação, havia um conjunto de dez problemas a serem resolvidos. Nota-se, pelo segundo exemplo, que a aprendizagem da subtração ocorria em conexão com a adição, pelo processo de completar ${ }^{2}$. Por certo, os resultados das testagens mostraram que esse processo era mais adequado ao ensino na escola primária.

Embora a linguagem escrita desempenhasse um papel fundamental na elaboração dos enunciados, outro fator a se considerar era a situação real, concreta, como ponto de partida para discussão em sala de aula. Nesse sentido, era de fundamental importância que o professor incentivasse as crianças a selecionarem da própria vida infantil, da casa ou do recreio, problemas práticos para que resolvessem na escola, de modo que se viabilizasse a conexão entre os problemas aritméticos e as coisas vivenciadas no cotidiano. Para Washburne (1927c), muitos dos erros cometidos na resolução de problemas eram indicativos de que o professor não dava exemplos práticos suficientes para as crianças trabalharem. Cabia ao professor trazer, ou despertar, o aspecto aritmético de qualquer projeto em que o aluno estivesse envolvido, uma vez que a quantidade de problemas apresentados na coleção não seria suficiente para dar a facilidade desejável na resolução de problemas. A quantidade de problemas deveria ser complementada por situações decorrentes de projetos, nos quais se demandassem naturalmente os conhecimentos aritméticos. No entanto, não se tratava de elaborar projetos específicos com objetivo de ensinar aritmética, tal como a criação de uma loja de brinquedos, mas aproveitar situações que emergissem nos vários tipos de projetos, ou das próprias crianças, quando trouxessem para a escola problemas que encontrassem fora dela. Mais do que desenvolver habilidades de resolução, os problemas apresentados tinham por função ilustrar o tipo de situação real a se trabalhar na escola primária e testar a capacidade dos alunos.

A coleção evidencia que o treino por meio de exercícios, organizados segundo a ordem psicológica das crianças, seria o fator que mais contribuiria para a aquisição da exatidão, rapidez na execução das operações e resolução de problemas aritméticos. No entanto, a quantidade de treinamento necessário e suficiente para calcular com rapidez e perfeição não dependia da vontade do professor, mas da capacidade de cada aluno, e do método de cálculo empregado, quando de domínio do professor.

${ }^{2}$ Processo pelo qual a criança toma a quantidade menor como ponto de partida para contar até a quantidade desejada. 


\section{Os estudos de Washburne como referência na formação de professores brasileiros}

As ideias educacionais de Washburne, bem como suas experiências desenvolvidas em Winnetka, não tardaram a cruzar as fronteiras estadunidenses. Por meio da publicação de artigos, livros, cursos ministrados no Teacher College, viagens nacionais e internacionais e das relações de cooperação com colegas de universidades, Washburne tornou o sistema pedagógico de Winnetka conhecido em todo o mundo.

No Brasil, suas investigações passam a circular por meio de textos traduzidos por estudantes de Escolas Normais ou como referências em textos elaborados por técnicos em educação, por professores de institutos de educação, e autores de manuais pedagógicos. Nota-se que os discursos veiculados nessas publicações davam visibilidade e legitimidade a um grupo de profissionais detentores de "[...] um tipo específico de saber, aquele que sustenta e determina o poder de conquistar para si um lugar próprio" (CERTEAU, 2012, p. 94). Em um contexto de ideias escolanovistas que se assentavam no país, de teorias educacionais que justificavam uma nova formação aos professores, os estudos de Washburne se apresentaram como modelo viável na justificativa de modificações para o ensino de aritmética da escola primária, na reorganização do programa segundo a maturidade infantil, com foco nos saberes necessários à sociedade. (PINHEIRO, 2020).

No caso de institutos de educação, as referências aparecem de modo direto ou indireto, como no curso de cálculo ofertado pela Escola de Professores do Instituto de Educação do Distrito Federal, no Rio de Janeiro. Sob a responsabilidade da professora Alfredina de Paiva Souza (SOUZA, 1937), as investigações de Washburne aparecem, em referência direta, como suporte para discussão e pesquisas sobre a aprendizagem dos processos de calcular, com foco na variação das dificuldades apresentadas pelas combinações dos fatos aritméticos, e da solução de problemas aritméticos. E, de modo indireto, via seleção de manuais pedagógicos que fazem citação às investigações de Washburne. Na capital mineira, ao que tudo indica, sua coleção de aritméticas serviu como suporte à prática pedagógica da professora Alda Lodi, enviada pelo governo de Minas Gerais para uma especialização em educação com foco em Metodologia da Aritmética, no Teachers College, da Universidade de Columbia, em Nova lorque. Em 1929, ela retornou a Belo Horizonte, quando passou a atuar na recém-criada Escola de Aperfeiçoamento. Por certo, na época, Alda Lodi entrou em contato com os estudos de Washburne, tendo adquirido sua coleção de aritméticas, publicada em 1927. Indícios de sua apropriação podem ser vistos no caderno de uma de suas alunas, ao adotar o uso de cartões com combinações numéricas de um lado e o resultado no verso (KULESZA, 2019). Em São Paulo, professores das Escolas Normais indicam as investigações de Washburne na seleção de problemas e na elaboração de programas científicos para a escola primária. (ALVES, 1944; ESCOBAR, 1934).

\section{Considerações finais}

A aspiração inicial deste texto foi analisar as investigações científicas realizadas sob supervisão de Washburne, a fim de melhor compreender quais resultados foram sistematizados e transformados em orientações pedagógicas. Ao analisar suas primeiras publicações nota-se como sua expertise pedagógica foi sistematizada, e as 
ferramentas de sua própria prática foram padronizadas, na relação com elementos disciplinares do campo da aritmética, da estatística, da pedagogia e da psicologia, enriquecendo e desenvolvendo novos conhecimentos, cada vez mais precisos, sobre o sistema escolar. Seus estudos evidenciam os primeiros passos na elaboração de saberes sobre o ensino de aritmética, fundamentados em novos objetivos e em uma nova organização curricular, que vão melhor delimitar o campo do ensino de matemática na escola primária.

Do ponto de vista da aprendizagem, tem-se um novo entendimento sobre o processo de memorização, que deixa de se basear na simples repetição mecânica de conceitos logicamente estruturados, passando a ser consequência do ensino psicologicamente organizado. Por esse processo, a aprendizagem necessita da memória para fixação e reprodução do que se aprendeu, envolvendo um conjunto de técnicas estabelecidas por investigações científicas, que consistem na elaboração de materiais específicos. Tais técnicas consideram o número de repetições, bem como sua distribuição ao longo do material, as condições mentais e subjetivas dos alunos, como atenção, interesse, prática e as diferenças individuais. Apesar de considerar as condições subjetivas do sujeito que aprende, as orientações sistematizadas nos materiais elaborados por Washburne focaram na memória mecânica, deixando em segundo plano a memória lógica, aquela ligada às relações de significação, de compreensão do assunto. No caso dos problemas aritméticos, ainda que fossem de aplicação prática, houve significativas modificações em sua elaboração. Na análise dos textos de Washburne, embora não se apresentem as reflexões teóricas, advindas da psicologia, que justifiquem os resultados de seus experimentos, evidencia-se que o processo de ensino deveria, inicialmente, desenvolver conceitos ligados à concretude do cálculo, à automatização da mecânica da aritmética para, posteriormente, desenvolver-se o raciocínio.

Quanto às orientações pedagógicas, Washburne não difunde modelos de práticas a serem seguidos pelos professores, mas modos de se pensar a prática, equilibrar conteúdos, métodos e as diferenças individuais em um mesmo contexto: o da escola primária. A busca por esse equilíbrio evidencia que não basta mais o professor saber apenas os conteúdos matemáticos e os métodos pelos quais ensinar, tais como eles são dados pela Academia, mas é preciso ter conhecimentos sobre o que, quando e como ensinar de modo a tornar a aritmética ensinável, e isso implica saber graduar dificuldades, elaborar problemas, escolher estratégias de resolução, saber treinar e saber revisar.

\section{Agradecimentos}

O presente trabalho foi realizado com apoio da Fundação de Amparo à Pesquisa do Estado de São Paulo (FAPESP), Processo no 18/24382-3, vigência 1/3/2019 a 28/02/2022.

\section{Referências}

ALVES, M. B. C. Como selecionar os problemas de aritmética para a escola primária. Educação, São Paulo, v. 31, p. 142 -144, 1944. Disponível em: https://cutt.ly/lQyCOBw. Acesso em: 23 set. 2019. 
BERTINI, L. F.; MORAIS, R. S.; VALENTE, W. R. A matemática a ensinar e a matemática para ensinar: novos estudos sobre a formação de professores. São Paulo: Livraria da Física, 2017.

BROWNELL, W. A. A critique of the committee of seven's investigations on the grade placement of arithmetic topics. Elementary School Journal, Chicago, v. 28, n. 7, p. 495-508, Mar. 1938.

CERTEAU, M. A invenção do cotidiano 1: artes do fazer. Petrópolis: Vozes, 2012.

CHARTIER, R. A história cultural: entre práticas e representações. Lisboa: Difel; Rio de Janeiro: Bertrand Brasil, 1990.

ESCOBAR, J. R. A construção científica dos programas: I parte : o problema teorico: as bases psicosociológicas dos programas. São Paulo: Imprensa Oficial do Estado, 1934.

HOFSTETTER, R.; SCHNEWUWLY, B.; FREYMOND, M. Penetrar na verdade da escola para ter elementos concretos de sua avaliação: a irresistível institucionalização do expert em educação (século XIX e XX). In: HOFSTETTER, R. VALENTE, W. (org.). Saberes em (trans)formação: tema central da formação dos professores. São Paulo: Livraria da Física, 2017. p. 55-112.

KILPATRICK, J. A history of research in mathematics education. In: GROUWS, D. A. (ed.). Hanbook of research on mathematics teaching and learning: a project of the National Council of Teachers of Mathematics. Reston: National Council of Teachers of Mathematics. 1992. p. 3-38.

KULESZA, W. A. A escola de aperfeiçoamento de Belo Horizonte. Curitiba: Appris, 2019.

MEUER, W. G. Carleton W. Washburne: his administrative and curricular contributions in the Winnetka public schools, 1919, through 1943. 1988. 267 p. Dissertation (Doctor of Education) Loyola University Chicago, Chicago, 1988.

MILLER, G. H. How much time for arithmetic? The Arithmetic Teacher, Washington, v. 5, n. 5, p. 256-259, nov. 1958. Disponível em: https://www.jstor.org/stable/41184085. Acesso em: 23 set. 2019.

MORAIS, R. S.; VALENTE, W. R. Os experts e o saber profissional do professor que ensina matemática. Ciência \& Educação, Bauru, v. 26, e20029, p. 1-13, 2020. DOI: https://doi.org/gpwc.

PINHEIRO, N. V. L.; VALENTE, W. R. Carleton Washburne e as pesquisas sobre a aritmética nos primeiros anos escolares. Revista Pesquisa Qualitativa, São Paulo, v. 4, n. 4, p. 88-105, 2016. Disponível em: https://editora.sepq.org.br/rpq/article/view/33. Acesso em: 23 set. 2019.

PINHEIRO, N. V. L. A aritmética sob medida: a matemática em tempos da pedagogia científica. 2017. 214 f. Tese (Doutorado em Ciências) - Universidade Federal de São Paulo, Guarulhos, 2017.

PINHEIRO, N. V. L. A matemática profissional na formação de professores. HISTEMAT, São Paulo, v. 6, n. 2, p. 155-169, 2020. Disponível em: https://cutt.ly/7QyNZK5. Acesso em: 23 jul. 2021.

PINHEIRO, N. V. L. Entre produção e circulação: os estudos de Carleton Washburne via publicações da New Education Fellowship. Revista Brasileira de História da Educação, Maringá, v. 21, e.147, 2021a. Disponível em: https://cutt.ly/dQyMqeY. Acesso em: 21 jul. 2021.

PINHEIRO, N. V. L. Viagens, parcerias e a circulação dos estudos de Washburne via congressos da New Education Fellowship. [2021b]. Livro eletrônico. (No prelo).

RABELO, R. S. Destinos e trajetos: Edward Lee Thorndike e John Dewey na formação matemática do professor primário no Brasil (1920-1960). Tese (Doutorado em Educação) - Universidade de São Paulo, São Paulo, 2016.

RATHS, L. E. Grade-placement of addition and subtraction of fractions. Educational Research Bulletin, Columbus, v. 11, n. 2, p. 29-38, 1932a.

RATHS, L. E. The last word: a reply to Mr. Washburne's rebuttal. Educational Research Bulletin, Columbus, v. 11, n. 15, p. 405-409, 1932 b. 
SOUZA, A. P. Cálculo. Arquivos do Instituto de Educação, Rio de Janeiro, v. 1, n. 3, p. 323-327, 1937.

WASHBURNE, C. W. Arithmetic grade-placement investigations of the Committee of Seven: a reply to Louis E. Raths. Educational Research Bulletin, Columbus, v. 11, n. 15, p. 396-410, 1932.

WASHBURNE, C. W. A comparison of two methods of teaching pupils to apply the mechanics of arithmetic to the solution of problems. Elementary School Journal, Chicago, v. 27, n. 10, p. 758$767,1927 a$.

WASHBURNE, C. W. La escuela individualizada. Madrid: Publicaciones de la Revista de Pedagogía, 1934.

WASHBURNE, C. W. Social practices in arithmetic fundamentals. Elementary School Journal, Chicago, v. 27, n. 1, p. 60-66, 1926.

WASHBURNE, C. W. Washburne individual arithmetic: teacher's manual books one to five. Chicago: World Book Company, 1927b.

WASHBURNE, C. W. Washburne individual arithmetic: books one to five. Chicago: World Book Company, 1927c.

WASHBURNE, C. W. When should we teach arithmetic?: a committee of seven investigation. Elementary School Journal, Chicago, v. 28, n. 9, p. 659-665, 1928.

WASHBURNE, C. W. The work of the Committee of Seven on grade placement in arithmetic. In: 38th YEARBOOK of the National Society for the Study of education. Chicago: University of Chicago Press, 1939. p. 299-324.

WASHBURNE, C. W.; MARLAND, S. P. Winnetka: the history and significance of an educational experiment. Englewood Cliffs: Prentice-Hall, 1963.

WASHBURNE, C.; MORPHETT, M. V. Unfamiliar situations as a difficulty in solving arithmetic problems. The Journal of Educational Research, Washington, v. 18, n. 3, p. 220-224, 1928.

WASHBURNE, C. W.; OSBORNE, R. Solving arithmetic problems I. Elementary School Journal, Chicago, v. 27, n. 3, p. 219-226, 1926 a.

WASHBURNE, C. W.; OSBORNE, R. Solving arithmetic problems II. Elementary School Journal, Chicago, v. 27, n. 4, p. 296-304, 1926b.

ZILVERSMIT, A. Changing schools: progressive education theory and practice, 1930-1960. Chicago: The University of Chicago Press, 1993. 